\title{
Genomic DNA fingerprinting of clinical Haemophilus influenzae isolates by polymerase chain reaction amplification: comparison with major outer-membrane protein and restriction fragment length polymorphism analysis
}

\author{
A. VAN BELKUM*, BIRGITTA DUIM†, ANNETTE REGELINK†, LIEKE MÖLLER $† \S$, WIM QUINT*† \\ and L. VAN ALPHEN $\dagger$
}

* Diagnostisch Centrum SSDZ, Department of Molecular Biology, PO Box 5010, 2600 GA Delft; † University of Amsterdam, Academic Medical Center, Department of Medical Microbiology, Meibergdreef 15, 1105 AZ Amsterdam; $\ddagger$ University Hospital Dijkzigt, Department of Virology, Dr. Molewaterplein 40, 3015 GD Rotterdam and $\$$ Laboratory for Public Health Groningen and Department of Medical Microbiology, University Hospital Groningen, Oostersingel 59, 9713 EZ Groningen. The Netherlands

\begin{abstract}
Summary. Non-capsulate strains of Haemophilus influenzae were genotyped by analysis of variable DNA segments obtained by amplification of genomic DNA with the polymerase chain reaction (PCR fingerprinting). Discrete fragments of $100-2000$ bp were obtained. The reproducibility of the procedure was assessed by comparing: (i) the fingerprints of 16 colonies of a single $H$. influenzae strain; (ii) isolates obtained from individual sputum samples (a total of $57 \mathrm{H}$. influenzae isolates from three cystic fibrosis patients); and (iii) 17 isolates collected during an outbreak of $H$. influenzae infection in a local pulmonary rehabilitation centre. The discriminatory power of the method was demonstrated by showing that the PCR fingerprints of eight unrelated $H$. infuenzae strains from sputum samples of patients with chronic obstructive pulmonary disease (COPD) and 32 strains from cystic fibrosis patients were all different. These 40 isolates also differed with respect to their restriction fragment length polymorphisms (RFLP) and major outer-membrane protein (MOMP) composition. Twelve MOMP antigenic strain variants from sputum samples of five COPD patients had identical PCR fingerprints and RFLPs. It was concluded that PCR fingerprinting is a reliable and reproducible method for genotyping non-capsulate strains of $H$. influenzae. The discriminatory power of PCR fingerprinting was similar to that of RFLP analysis, but the results of PCR fingerprinting were easier to interpret.
\end{abstract}

\section{Introduction}

Haemophilus influenzae is found exclusively in man. Non-capsulate strains cause acute and persistent infections of the mucous membranes and colonise the nasopharynx of a high percentage of healthy individuals. ${ }^{1}$ Throat cultures of children can remain positive for a particular $H$. influenzae strain for several months. ${ }^{2,3}$ In patients with chronic obstructive pulmonary disease (COPD) and cystic fibrosis (CF), $H$. influenzae is isolated frequently from sputum samples. ${ }^{4,5}$ However, the availability of highresolution bacterial typing assays is a pre-requisite for the study of $H$. influenzae epidemiology.

Non-capsulate $H$. influenzae isolates are charac-

Correspondence to Dr A. van Belkum, Academic Hospital Dijkzigt, Department of Clinical Microbiology, Dr Molewaterplein 40, 3015 GD Rotterdam, The Netherlands.

Received 20 Dec. 1993; accepted 28 Jan. 1994. terised commonly by major outer-membrane protein (MOMP) analysis with SDS-PAGE. This method is highly discriminatory because of strong inter-strain variability. ${ }^{6-9}$ However, MOMP patterns have been shown to change during persistent $H$. influenzae infections in patients with COPD. ${ }^{10.11}$ Antigenic diversity of lipopolysaccharides (LPS), which may also be used to characterise non-typable $H$. influenzae strains, ${ }^{12}$ is difficult to interpret because LPS undergoes phase variation at high frequency. ${ }^{13}$ Of the genotypic methods, multilocus enzyme electrophoresis, ${ }^{14}$ rRNA gene restriction pattern analysis ${ }^{15}$ and DNA restriction fragment length polymorphism (RFLP) analysis have been applied successfully to differentiate isolates. ${ }^{10,11,16}$ However, since multilocus enzyme electrophoresis is very laborious, rRNA gene restriction pattern analysis has a low discriminatory power, and RFLP analysis results in over-complex banding patterns, there is a clear need for a novel discriminatory typing method. 
a

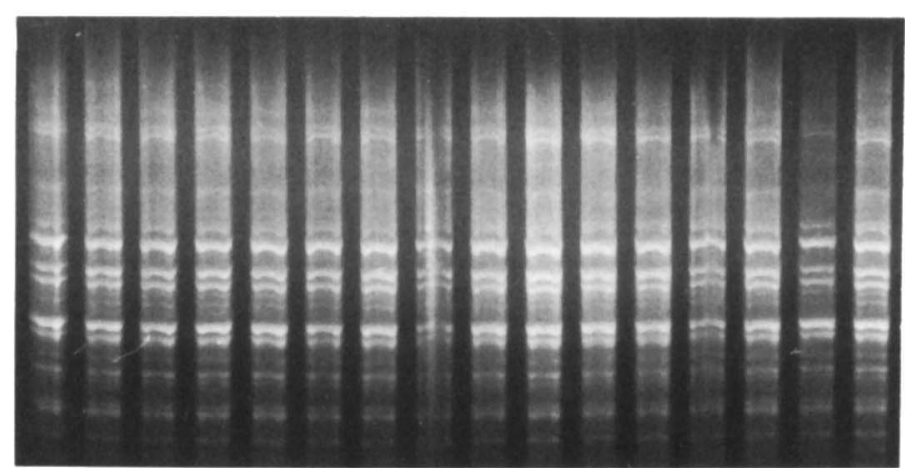

b

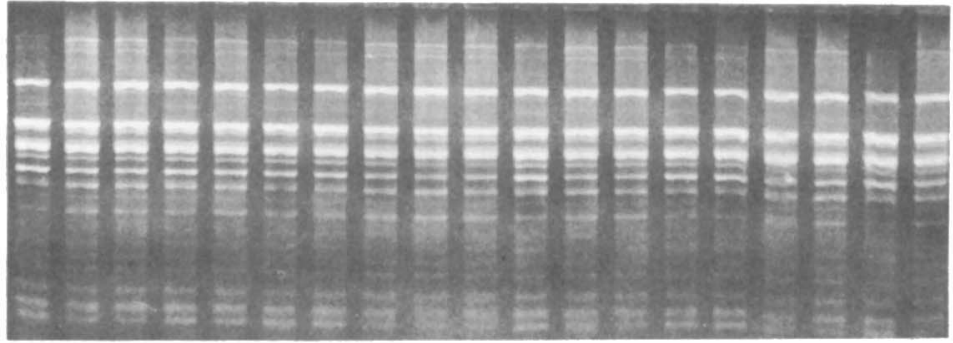

C

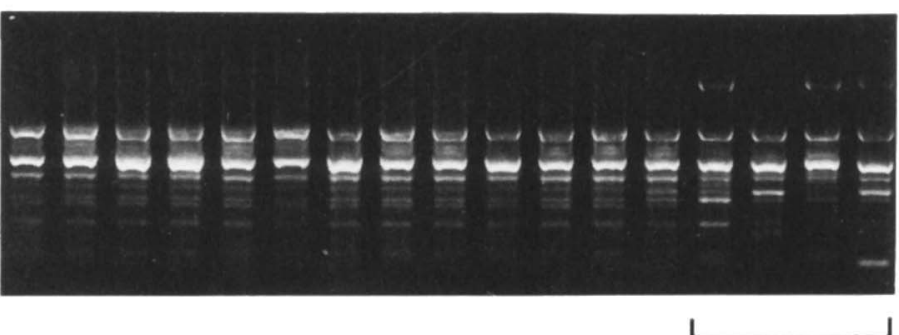

bp

$-2000$

$-500$

$-1600$

$-300$

$-1600$

$-300$

Fig. 1. Analysis of the reproducibility of PCR fingerprinting of $H$. influenzae strains with a combination of the ERIC1R and the ERIC2 primers: a, fingerprints obtained from 16 colonies from a single strain cultivated on one chocolate agar plate; $\mathbf{b}$, fingerprints obtained from 19 independent $H$. influenzae isolates from primary cultures of sputum samples from a CF patient; $\mathbf{c}$, fingerprints of $13 H$. influenzae strains collected from 13 COPD patients during an outbreak in a pulmonary rehabilitation clinic. The four righthand lanes show PCR fingerprints from non-related $H$. influenzae isolates.

A potential alternative procedure for the rapid detection of genetic diversity is now available. ${ }^{17-19}$ For many prokaryotic and eukaryotic micro-organisms, it has been shown that fingerprints can be generated after amplification of genomic DNA with random primers in the polymerase chain reaction (PCR). ${ }^{20-24}$ The genetic basis of the variation in such PCR fingerprints is two-fold. Firstly, DNA sequence variations can be detected by a combination of short, arbitrarily chosen primers and low-stringency hybridisation conditions during the PCR. Secondly, a PCR assay can be aimed at hypervariable regions of the genome surrounded by repetitive sequences that are recognised by specific PCR primers. ${ }^{23,25,26}$

In the present study, genomic DNA amplified by PCR with primers for the enterobacterial repetitive intergenic consensus (ERIC) sequence ${ }^{26}$ was used to genotype non-capsulate $H$. influenzae isolates. The discriminatory power of PCR fingerprinting was compared with RFLP genotyping and MOMP analysis. The reproducibility and specificity of PCR fingerprinting was analysed with epidemiologically welldefined $H$. influenzae isolates, obtained from COPD and $C F$ patients, which had been characterised previously by RFLP and MOMP analyses. ${ }^{10.11}$ In ad- dition, the PCR fingerprints of $H$. influenzae strains were compared with those of other Haemophilus species.

\section{Materials and methods}

\section{Bacterial strains and DNA isolation}

Non-capsulate $H$. influenzae strains were isolated either from sputum samples obtained from COPD patients during an epidemiological study of persistent $H$. influenzae infections in these patients, ${ }^{4,10,11}$ or from sputum samples from COPD patients in a pulmonary rehabilitation centre during a local outbreak of multiresistant $H$. influenzae infection. ${ }^{27} H$. parainfluenzae strains were isolated from sputum obtained from COPD patients or from throat swabs of healthy carriers. $H$. haemoglobinophilus and $H$. haemolyticus strains were obtained from I. I. Falsen, Department of Clinical Microbiology, University of Göteborg, Sweden. All haemophili were inoculated on to chocolate agar plates from stocks stored at $-70^{\circ} \mathrm{C}$ in nutrient broth supplemented with glycerol $15 \% \mathrm{v} / \mathrm{v}$, and were then incubated for $16 \mathrm{~h}$ at $37^{\circ} \mathrm{C}$ in a humid 
a
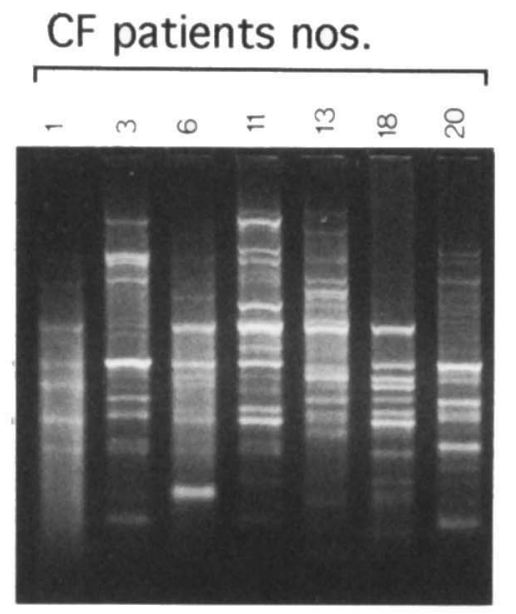

COPD patients nos.

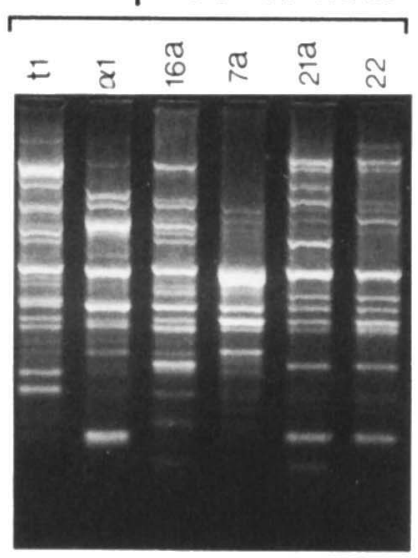

$-1600$

$-300$

$-1600$

$-300$

$-1600$

$-300$

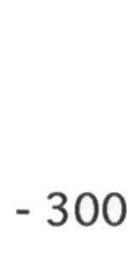

C
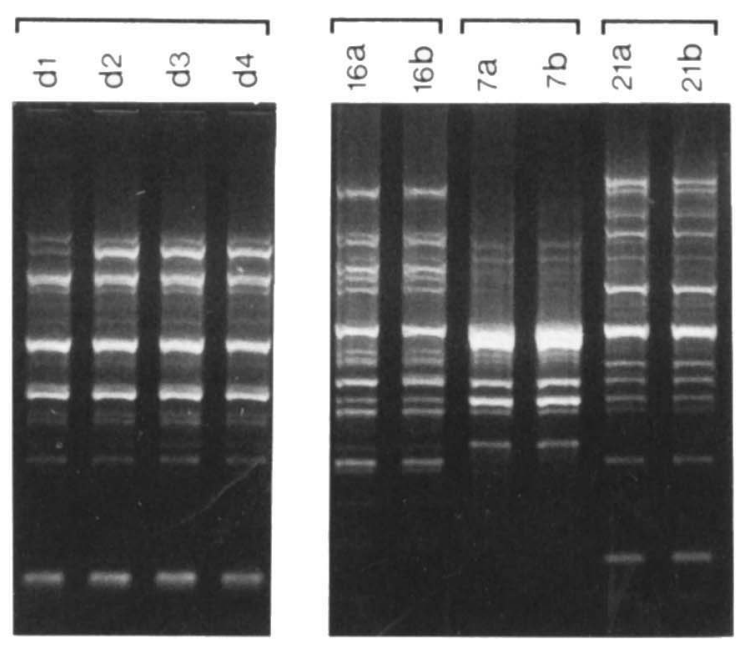

Fig. 2. PCR fingerprints obtained with primers ERICIR and ERIC2 from clinical $H$. influenzae isolates and strains belonging to other Haemophilus spp: a, strains from a selected group of CF patients $(1,3,6,11,18$ and 20) and COPD patients (P, T, K, D and M; see table); b, eight $H$. parainfluenzae strains (Hp1-8); two H. haemolyticus strains (Hh1-2) and one H. haemoglobinophilus strain (Hhg); c, H. influenzae antigenic strain variants from COPD patients T (d1-d4), K (16a and 16b), D (7a and 7b) and M (21a and 21b).

atmosphere enriched with $\mathrm{CO}_{2} 5 \%$. For the analysis of MOMPs, $c$. five colonies were inoculated into $10 \mathrm{ml}$ of brain heart infusion broth and incubated overnight at $37^{\circ} \mathrm{C}$ with shaking at $120 \mathrm{rpm}$. The resulting cells were harvested by centrifugation. ${ }^{9}$ For DNA isolation, bacterial growth was scraped from the plates and resuspended in $2 \mathrm{ml}$ of phosphate-buffered saline

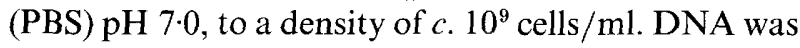
isolated from $250 \mu \mathrm{l}$ of this suspension by the guanidium isothiocyanate" "protocol described previously. ${ }^{24,28}$ The DNA concentration was estimated by comparing a small DNA sample stained with ethidium bromide with known amounts (10-500 ng) of bacteriophage lambda DNA. Finally, DNA was dissolved at a concentration of $c .10 \mathrm{ng} / \mu 1$ in $10 \mathrm{~mm}$ Tris-HCl, pH 8.0, 1 mm EDTA.

\section{MOMP analysis and RFLP determination}

MOMP typing was by SDS-PAGE as described by Lugtenberg et al..$^{29}$ and modified by van Alphen et al. ${ }^{9}$ RFLP fingerprinting after restriction endonuclease treatment of total genomic DNA was as described previously. ${ }^{11}$ 


\section{PCR fingerprinting}

The PCR reaction buffer consisted of $10 \mathrm{~mm}$ Tris$\mathrm{HCl}, \mathrm{pH} 9 \cdot 0,50 \mathrm{~mm} \mathrm{KCl}, 2.5 \mathrm{~mm} \mathrm{MgCl}_{2}$, gelatin $0.01 \% \mathrm{w} / \mathrm{v}$ and Triton X100 $0.1 \% \mathrm{v} / \mathrm{v}$. Each reaction included primers ERIC1R and ERIC2 ${ }^{24,26}$ (50 pmol each), deoxyribonucleotide triphosphates (final concentration of $0.2 \mathrm{~mm}$ each), sample DNA (c. $50 \mathrm{ng}$ ), $0.5 \mathrm{U}$ of Taq DNA polymerase (Sphaero Q, Leiden, The Netherlands). The arbitrary primer BG2 (50 pmol/reaction)-5'TACATTCGAGGACCCCTAAGTG-3' - was included as an alternative for one of the ERIC primers in some experiments. The PCR was initiated with a 5 -min denaturation period at $94^{\circ} \mathrm{C}$, followed by 35 cycles of denaturation $\left(1 \mathrm{~min}\right.$ at $94^{\circ} \mathrm{C}$ ), annealing $\left(1 \mathrm{~min}\right.$ at $\left.25^{\circ} \mathrm{C}\right)$ and enzymic chain extension $\left(4 \mathrm{~min}\right.$ at $74^{\circ} \mathrm{C}$ ). Finally, an additional 10 -min DNA extension step at $74^{\circ} \mathrm{C}$ was included. The PCR reactions were performed with a Model 60 Thermocycler (Biomed, Theres, Germany). DNA fingerprints were visualised by ethidium bromide staining of agarose $1-3 \% \mathrm{w} / \mathrm{v}$ gels run in $40 \mathrm{~mm}$ Tris-acetate, $\mathrm{pH} 7 \cdot 8$, $2 \mathrm{~mm}$ EDTA, and were then photographed with Polaroid Polapan film. Results were analysed only if control samples without extraneous sample DNA failed to yield amplified DNA. Analysis of the PCR fingerprinting data was performed blind with respect to the RFLP and MOMP typing data.

\section{Results}

General characteristics, reproducibility and stability of the PCR fingerprints of non-capsulate $H$. influenzae isolates

PCR with primers ERIC1R and ERIC2 produced complex banding patterns on agarose gels (figs. 1 and 2), with fragments of $100-c .2000 \mathrm{bp}$ in size. In contrast, PCR with the arbitrary primer BG2 in combination with one of the ERIC primers resulted in fewer bands in trial experiments with 10 strains of $H$. influenzae. Therefore, PCR with primers ERIC1R and ERIC2 was chosen for further analysis.

To assess whether reproducible banding patterns were generated by PCR fingerprinting, 16 colonies from a pure culture of a single $H$. influenzae strain obtained from the sputum of a CF patient were analysed. Fig. 1a shows that the 16 corresponding fingerprints appeared to be monomorphic. Minor differences in the staining intensity of the lanes probably resulted from differences in template DNA concentration as a consequence of variations in the original colony size. Next, PCR fingerprinting was performed on multiple $H$. influenzae isolates obtained from the primary cultures of sputum from three individual CF patients. Fig. $1 \mathrm{~b}$ shows that 19 isolates from one primary sputum culture of one CF patient had identical DNA fingerprints. These isolates also had identical MOMP profiles and RFLP patterns (results not shown). Similar results were obtained with
19 isolates from the primary culture of sputum from a second CF patient. A third CF patient was infected by two apparently different $H$. influenzae strains, based on analysis of DNA patterns and MOMP profiles. These 19 isolates fell into two distinct groups (three and 16 isolates, respectively). Similar results were obtained when the isolates from the three CF patients were analysed on different days.

The stability of the PCR fingerprints was examined by comparing 17 isolates from a local outbreak of infection caused by multi-resistant non-capsulate $H$. influenzae in a pulmonary rehabilitation centre. ${ }^{23}$ Thirteen isolates from different individuals were studied. Fig. 1c shows that these strains, shown previously to have identical MOMP patterns, ${ }^{27}$ also had identical PCR fingerprints. The PCR fingerprints, MOMPs ${ }^{27}$ and RFLPs (results not shown) of these 13 identical strains differed clearly from those of the four unrelated strains also obtained during the local outbreak, as exemplified by the PCR fingerprints in the four righthand tracks of fig. $1 \mathrm{c}$.

\section{Diversity of PCR fingerprints of unrelated non- capsulate $H$. influenzae}

The variation in PCR fingerprints was investigated with six non-capsulate $H$. influenzae strains obtained

Table. Characteristics of $H$. influenzae strains from patients with chronic obstructive pulmonary disease (COPD) or cystic fibrosis $(\mathrm{CF})$

\begin{tabular}{|c|c|c|c|c|}
\hline Patient* & $\begin{array}{c}\text { Strain } \\
\text { no. }\end{array}$ & $\begin{array}{c}\text { PCR } \\
\text { pattern } \dagger\end{array}$ & $\begin{array}{c}\text { RFLP } \\
\text { type }\end{array}$ & $\begin{array}{c}\text { MOMP } \\
\text { type } \ddagger\end{array}$ \\
\hline $\mathrm{CF} 1$ & $41 / z$ & A & $\S$ & $\S$ \\
\hline CF3 & $42 / z$ & B & $\S$ & $\S$ \\
\hline CF6 & $43 / z$ & $\mathrm{C}$ & $\S$ & $\S$ \\
\hline CF 11 & $44 / z$ & D & $\S$ & $\S$ \\
\hline CF13 & $22 / \mathrm{z}$ & $\mathbf{E}$ & $\S$ & $\S$ \\
\hline CF18 & $23 / z$ & $\mathbf{F}$ & $\S$ & $\S$ \\
\hline CF 20 & $26 / a$ & G & $\S$ & $\S$ \\
\hline \multirow[t]{2}{*}{ COPD P } & $\mathrm{tl}$ & $\mathrm{H}$ & I & $1 a$ \\
\hline & $\mathrm{t} 2$ & $\mathrm{H}$ & I & $1 b$ \\
\hline \multirow[t]{4}{*}{ COPD T } & d1 & I & II & $2 a$ \\
\hline & $\mathrm{d} 2$ & I & II & $2 b$ \\
\hline & d3 & I & II & $2 c$ \\
\hline & $\mathrm{d} 4$ & I & II & $2 d$ \\
\hline \multirow[t]{2}{*}{ COPD K } & $16 a$ & $\mathbf{J}$ & III & $3 a$ \\
\hline & $16 \mathrm{~b}$ & $\mathbf{J}$ & III & $3 b$ \\
\hline \multirow[t]{2}{*}{ COPD D } & $7 \mathrm{a}$ & $\mathrm{K}$ & IV & $4 a$ \\
\hline & $7 \mathrm{~b}$ & $\mathrm{~K}$ & IV & $4 b$ \\
\hline \multirow[t]{3}{*}{ COPD M } & $21 \mathrm{a}$ & $\mathrm{L}$ & V & $5 \mathrm{a}$ \\
\hline & $21 b$ & $\mathrm{~L}$ & $\mathrm{~V}$ & $5 b$ \\
\hline & 22 & M & VI & 6 \\
\hline
\end{tabular}

* Different isolates from individual patients were obtained from samples taken at intervals of at least 1 month.

$\dagger$ Different PCR fingerprints are represented by capital letters, each of which indicates a unique DNA banding pattern.

$\ddagger$ All isolates from CF patients had different RFLP and MOMP types (indicated by $\S$ ). Different RFLP patterns of isolates from COPD patients are indicated by Roman figures. MOMP patterns of non-related strains are indicated by numbers; antigenic strain variants are indicated by a lower case letter following the number. The latter data are taken from Groeneveld et al. ${ }^{10}$ 


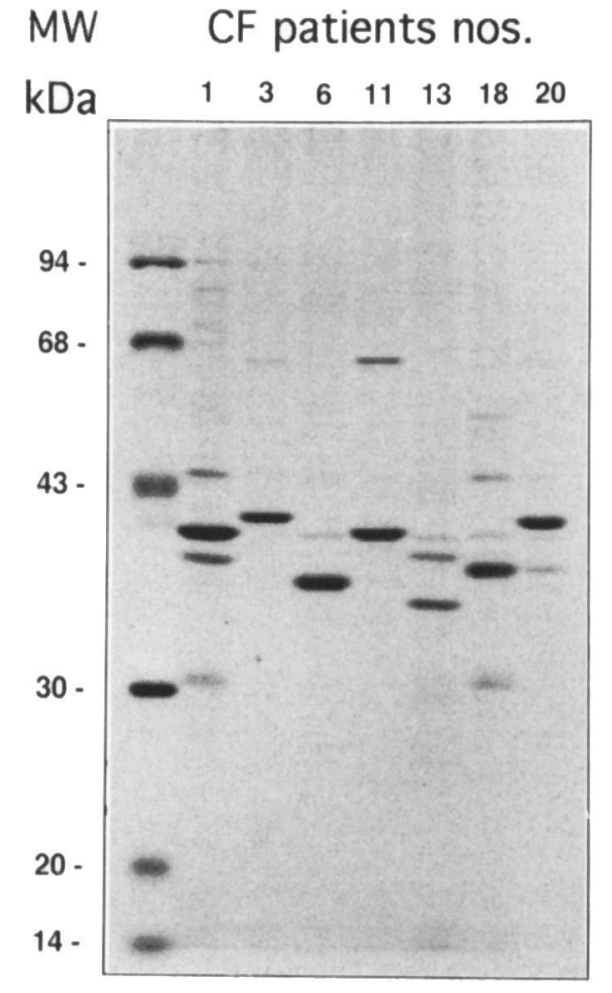

Fig. 3. Major outer-membrane protein (MOMP) patterns of seven non-related $H$. influenzae isolates from CF patients (table).

from five COPD patients and seven strains from seven $\mathrm{CF}$ patients. The six isolates from COPD patients were known to have different RFLP and MOMP patterns, ${ }^{10,11}$ as summarised in the table. The seven CF isolates also had different RFLP (results not shown) and MOMP patterns (fig. 3). PCR fingerprints of the COPD and CF isolates revealed marked differences between all isolates (fig. 2a). The PCR fingerprints of additional non-related COPD $(\mathrm{n}=2)$ and $\mathrm{CF}(\mathrm{n}=$ 25) $H$. influenzae isolates appeared also to be mutually different, indicating that this typing method was completely discriminatory.

The PCR fingerprints of $H$. parainfluenzae (fig. $2 \mathrm{~b}$, lanes 1-8), H. haemolyticus (fig. 2b, lanes 9 and 10) and $H$. haemoglobinophilus (fig. 2b, lane 11) isolates showed wide diversity.

\section{Analysis of antigenic strain variants of $H$. influenzae by PCR fingerprinting}

A total of 12 clinical isolates from five COPD patients was analysed. These isolates had been shown previously to be antigenic strain variants, ${ }^{10,11}$ and are listed in the table. These strain variants have identical RFLP patterns, but vary in MOMP composition, mainly in MOMPs P2 and P5. ${ }^{10,11}$ In four of five COPD patients studied, the PCR fingerprints of the strain variants were identical (patients $P, K, D$ and $M$ ). The PCR fingerprints of $H$. influenzae strain variants $\mathrm{d} 1-\mathrm{d} 4$ from patient $\mathrm{T}$ were identical, except for a difference in intensity in one of the bands (fig. 2a). The PCR fingerprints of the antigenic strain variants from four of the COPD patients are shown in fig. 2c. $H$. influenzae strains different by PCR fingerprinting were also different by RFLP analysis.

\section{Discussion}

PCR fingerprinting of non-capsulate $H$. influenzae isolates offers the possibility of a faster and easier highresolution genotyping method for epidemiological studies. Fig. 1 demonstrates that the DNA fingerprints obtained with the ERIC primers ${ }^{26}$ were reproducible for epidemic isolates and individual colonies of a single strain. Differences in DNA fingerprints were observed also for various $H$. parainfluenzae isolates, and between $H$. influenzae, $H$. parainfluenzae and other Haemophilus spp. (fig. 2a and b).

The epidemiological findings from PCR fingerprinting of $H$. influenzae isolates were in full agreement with those derived from RFLP analysis (table), indicating that both methods were equally discriminatory. Moreover, as both these techniques focus on different parts of the bacterial genome, it is likely that variations reflect random genomic differences. An advantage of PCR fingerprinting over RFLP analysis is the ease with which the results may be interpreted.

The value of PCR fingerprinting for studying the clinical epidemiology of $H$. influenzae infections is illustrated in fig. 1c for multi-resistant non-capsulate $H$. influenzae isolates obtained during a local outbreak of infections in a pulmonary rehabilitation centre. Furthermore, the observation that antigenic strain variants from the sputum of COPD patients ${ }^{10,11}$ had identical PCR fingerprints (table; fig. 2) indicates that PCR fingerprinting is also suitable for genotyping sequential $H$. influenzae isolates obtained during persistent and recurrent infections.

In conclusion, PCR fingerprinting of genomic DNA is a simple, reliable method for genotyping noncapsulate $H$. influenzae isolates. Combined with MOMP analysis, PCR fingerprinting allows the identification of antigenic strain variants appearing during persistent infections. PCR fingerprinting and RFLP analysis may be combined to facilitate identification of closely related isolates as they focus on different parts of the chromosome. Although the epidemiological findings from PCR fingerprinting are similar to those from RFLP data, PCR fingerprints are easier to interpret.

We gratefully acknowledge the technical assistance of Henny Grasselier, and thank L. Bowler and J. Dankert for their critical reading of the manuscript. 


\section{References}

1. Van Alphen L. Epidemiology and prevention of respiratory tract infections due to non-encapsulated Haemophilus influenzae. J Infect Dis 1992; 165: S177-180.

2. Kuklinska D, Kilian M. Relative proportions of Haemophilus species in the throat of healthy children and adults. Eur $J$ Clin Microbiol 1984; 3: 249-252.

3. Spinola SM, Peacock J, Denny FW, Smith DL, Cannon JG. Epidemiology of colonization by nontypable Haemophilus influenzae in children: a longitudinal study. J Infect Dis 1986; 154: 100-109.

4. Möller LVM, Ruijs GJ, Heijerman HGM, Dankert J, van Alphen L. Haemophilus influenzae is frequently detected with monoclonal antibody 8BD9 in sputum samples from patients with cystic fibrosis. J Clin Microbiol 1992; 30 : 2495-2497.

5. Murphy TF, Apicella MA. Nontypable Haemophilus influenzae: a review of clinical aspects, surface antigens, and the human immune response to infection. Rev Infect Dis 1987 9: $1-15$.

6. Barenkamp SJ, Munson RS, Granoff DM. Outer membrane protein and biotype analysis of pathogenic nontypable Haemophilus influenzae. Infect Immun 1982; 36: 535-540.

7. Loeb MR, Smith DH. Outer membrane protein composition in disease isolates of Haemophilus influenzae: pathogenic and epidemiological implications. Infect Immun 1980; 30: 709-717.

8. Murphy TF, Dudas KC, Mylotte YM, Apicella MA. A subtyping system for nontypable Haemophilus influenzae based on outer-membrane proteins. J Infect Dis 1983; 147 : 838-846.

9. van Alphen L, Riemens T, Poolman J, Zanen HC. Characteristics of major outer membrane proteins of Haemophilus influenzae. J Bacteriol 1983; 155: 878-885.

10. Groeneveld K, van Alphen L, Eijk PP, Visschers G, Jansen HM, Zanen HC. Endogenous and exogenous reinfections by Haemophilus influenzae in patients with chronic obstructive pulmonary disease: the effect of antibiotic treatment on persistence. $J$ Infect Dis $1990 ; 161: 512-517$.

11. Groeneveld K, van Alphen L, Eijk PP, Jansen HM, Zanen HC. Changes in outer membrane proteins of nontypable Haemophilus influenzae in patients with chronic obstructive pulmonary disease. $J$ Infect Dis $1988 ; 158$ : 360-365.

12. Campagnari AA, Gupta MR, Dudas KC, Murphy TF, Apicella MA. Antigenic diversity of lipooligosaccharides of nontypeable Haemophilus influenzae. Infect Immun 1987; 55: $882-887$.

13. Tolan RW, Munson RS, Granoff DM. Lipopolysaccharide gel profiles of Haemophilus influenzae type b are not stable epidemiological markers. J Clin Microbiol 1986; 24 223-227.

14. Musser JM, Barenkamp SJ, Granoff DM, Selander RK. Genetic relationships of serologically nontypable and serotype $b$ strains of Haemophilus influenzae. Infect Immun 1986; 52: 183-191.

15. Bruce KD, Jordens $\mathbf{J Z}$. Characterization of noncapsulate
Haemophilus influenzae by whole-cell polypeptide profiles, restriction endonuclease analysis, and rRNA gene restriction patterns. J Clin Microbiol 1991; 29: 291-296.

16. Loos BG, Bernstein JM, Dryja DM, Murphy TM, Dickinson DP. Determination of the epidemiology and transmission of nontypable Haemophilus influenzae in children with otitis media by comparison of total genomic DNA restriction fingerprints. Infect Immun 1989; 57: 2751-2757.

17. Welsh J, McClelland M. Fingerprinting genomes using PCR with arbitrary primers. Nucleic Acids Res 1990; 18: 7213-7218.

18. Welsh J, McClelland M. Genomic fingerprinting using arbitrarily primed PCR and a matrix of pairwise combinations of primers. Nucleic Acids Res 1991; 19: 5275-5279.

19. Williams JGK, Kubelik AR, Livak KJ, Rafalski JA, Tingey SV. DNA polymorphisms amplified by arbitrary primers are useful as genetic markers. Nucleic Acids Res 1990; 18: $6531-6535$.

20. Cancilla MR, Powell IB, Hillier AJ, Davidson BE. Rapid genomic fingerprinting of Lactococcus lactis strains by arbitrarily primed polymerase chain reaction with ${ }^{32} \mathrm{P}$ and fluorescent labels. Appl Environ Microbiol 1992; 58: $1772-1775$.

21. Jayarao BM, Bassam BJ, Caetano-Annollés G, Gresshoff PM, Oliver SP. Subtyping of Streptococcus uberis by DNA amplification fingerprinting. J Clin Microbiol 1992; 30: $1347-1350$.

22. Myers LE, Silva SVPS, Procunier JD, Little PB. Genomic fingerprinting of "Haemophilus somnus" isolates by using a random-amplified polymorphic DNA assay, $J$ Clin Microbiol 1993; 31 : 512-517.

23. van Belkum A, de Jonckheere J, Quint WGV. Genotyping Naegleria spp. and Naegleria fowleri isolates by interrepeat polymerase chain reaction. J Clin Microbiol 1992; 30: 2595-2598.

24. van Belkum A, Bax R, Peerbooms P, Goessens WHF, van Leeuwen N, Quint WGV. Comparison of phage typing and DNA fingerprinting by polymerase chain reaction for discrimination of methicillin-resistant Staphylococcus aureus strains. J Clin Microbiol 1993; 31 : 798-803.

25. Perring TM, Cooper AD, Rodriguez RJ, Parrar CA, Bellows TS. Identification of a whitefly species by genomic and behavioral studies. Science 1993; 259: 74-77.

26. Versalovic J, Koeuth T, Lupski JR. Distribution of repetitive DNA sequences in eubacteria and application to fingerprinting of bacterial genomes. Nucleic Acids Res 1991; 19 : 6823-6831.

27. Sturm AW, Mostert R, Rouing PJE, van Klingeren B, van Alphen L. Outbreak of multiresistant nonencapsulated Haemophilus influenzae infections in a pulmonary rehabilitation centre. Lancet $1990 ; 335: 214-216$

28. Boom R, Sol CJA, Salimans MMM, Jansen CL, Wertheim-van Dillen PME, van der Noordaa J. Rapid and simple method for purification of nucleic acids. J Clin Microbiol 1990; 28 : 495-503.

29. Lugtenberg B, Meijers J, Peters R, van der Hoek P, van Alphen L. Electrophoretic resolution of the 'major outer membrane' protein of Escherichia coli $\mathrm{K} 12$ into four bands. FEBS Lett 1975 ; 58: 254-258. 